\title{
Development and Validation of Marker-Aided Selection Methods for Wood Property Traits in Loblolly Pine and Hybrid Poplar
}

\section{Final Report}

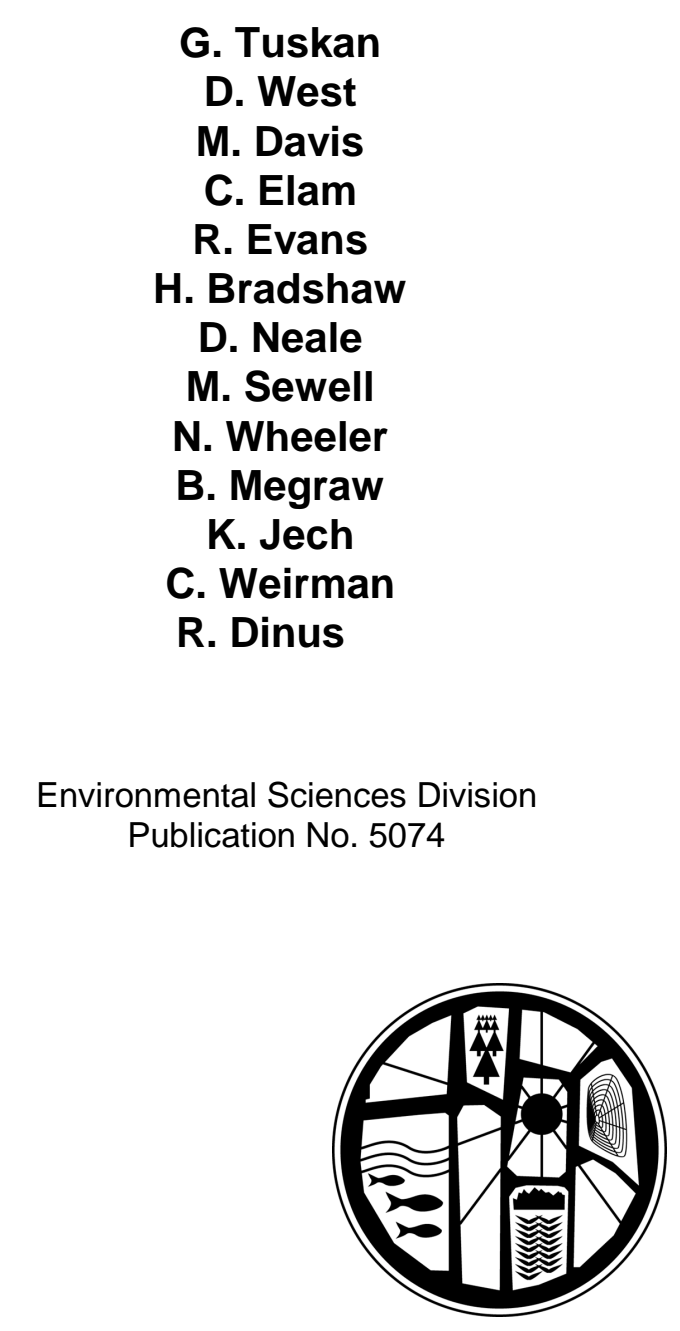


Environmental Sciences Division

\title{
DEVELOPMENT AND VALIDATION OF MARKER-AIDED SELECTION METHODS FOR WOOD PROPERTY TRAITS IN LOBLOLLY PINE AND HYBRID POPLAR - FINAL REPORT
}

\author{
G. Tuskan, D. West, ${ }^{1}$ M. Davis, C. Elam, R. Evans, ${ }^{2}$ H. Bradshaw,${ }^{3}$ D. Neale, \\ M. Sewell, ${ }^{4}$ N. Wheeler, B. Megraw, K. Jech, ${ }^{5}$ C. Weirman, ${ }^{6}$ and R. Dinus ${ }^{7}$
}

\footnotetext{
${ }^{1}$ Environmental Sciences Division, Oak Ridge National Laboratory

${ }^{2}$ National Renewable Energy Laboratory, Golden, Colorado

${ }^{3}$ University of Washington, Seattle, Washington

${ }^{4}$ U.S. Forest Service, Berkeley, California

${ }^{5}$ Weyerhaeuser Corp., Centralia, Washington

${ }^{6}$ Boise Cascade Corp., Wallula, Washington

${ }^{7}$ Private Consultant, Bellingham, Washington
}

Environmental Sciences Division

Publication No. 5074

Date Published: June 2001

Prepared for the

U.S. Department of Energy

Office of Industrial Technologies

Budget Activity Number ED 1801000

Prepared by

OAK RIDGE NATIONAL LABORATORY

Oak Ridge, Tennessee 37831

managed by

UT-BATTELLE, LLC.

for the

U.S. DEPARTMENT OF ENERGY

under contract DE-AC05-00OR22725 


\section{CONTENTS}

Page

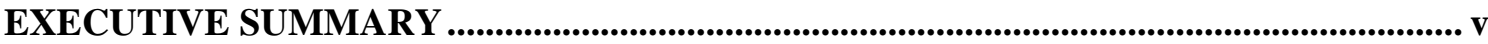

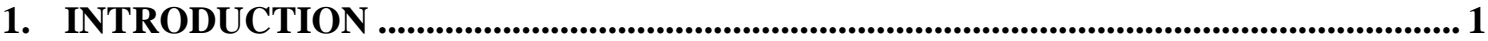

2. TWO HIGH-TROUGHPUT TECHNIQUES FOR DETERMINING WOOD PROPERTIES AS PART OF A MOLECULAR GENETICS ANALYSIS

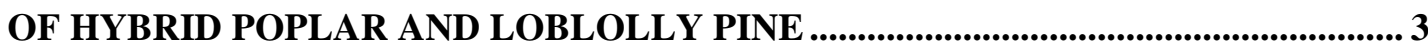

3. A RAPID METHOD FOR MEASURING SYRINGYL TO GUAIACYL RATIOS IN HARDWOODS USING PYROLYSIS MOLECULAR BEAM MASS SPECTROMETRY

4. IDENTIFICATION OF QTLS INFLUENCING WOOD PROPERTY TRAITS IN LOBLOLLY PINE (PINUS TAEDA L.). I. PHYSICAL WOOD PROPERTIES .5

5. IDENTIFICATION OF QTLS INFLUENCING WOOD PROPERTY TRAITS IN LOBLOLLY PINE (PINUS TAEDA L.). II. CHEMICAL WOOD PROPERTIES. 6

6. GENETIC VARIATION IN PHYSICAL AND CHEMICAL WOOD PROPERTY TRAITS IN HYBRID POPLAR (POPULUS SPP.) 7

7. GENETIC MODIFICATION OF SHORT ROTATION POPLAR WOOD PROPERTIES FOR ETHANOL FUEL AND FIBER PRODUCTION 8

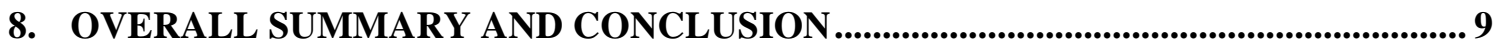

9. FUNDING INFORMATION .................................................................................................... 10

10. PRESENTATIONS, SCIENTIFIC PUBLICATIONS, AND WEB SITES 11 


\section{EXECUTIVE SUMMARY}

Wood properties influence pulp and paper quality. Certainly, overall pulp yields are directly related to the cellulose content, changes in hemicellulose content are associated with changes in pulp cohesiveness, and pulping efficiency is related to lignin content. Despite the importance of wood properties on product quality, little progress has been made in improving such traits because current methods of assessing wood and fiber characteristics are time-consuming, expensive, and often imprecise. Genetic improvement of wood and fiber properties has been further hampered by the large size of trees, delayed reproductive maturity and long harvest cycles. Recent developments in molecular genetics will help overcome the physical, economic and biological constraints in assessing and improving wood properties. Genetic maps consisting of numerous molecular markers are now available for loblolly pine and hybrid poplar. Such markers/maps may be used as part of a marker-aided selection and breeding effort or to expedite the isolation and characterization of genes and/or promoters that directly control wood properties.

The objectives of this project are: 1) to apply new and rapid analytical techniques for assessing component wood properties to segregating $\mathrm{F}_{2}$ progeny populations of loblolly pine and hybrid poplar, 2) to map quantitative trait loci and identify molecular markers associated with wood properties in each of the above species and 3) to validate marker-aided selection methods for wood properties in loblolly pine and hybrid poplar.

We have developed two rapid assays, pyrolysis molecular beam mass spectroscopy (pyMBMS) for cell wall chemical composition and computer-assisted tomography $\mathrm{x}$-ray densitometry (CT scan) for wood specific gravity, annual ring boundaries and within-ring specific gravity for Populus and loblolly pine. The techniques 1) can be completed in a fraction of the time ( 1-2 minutes per sample) typically required for traditional analytical methods and 2) utilize small subsamples or are non-destructive.

We have detected nine quantitative trait loci (QTLs) in loblolly pine for wood specific gravity (wsg) (explaining 34\% of variance) and 5 for microfibrile angle (mfa) (44\% variance). QTLs for wsg appear to be either early- or latewood specific, whereas QTLs for mfa were detected for both early- and latewood. Twelve unique QTLs influencing cell wall chemistry (cwc) were detected using the one-QTL model and most QTLs (75\%) were verified by analyses of multiple peak values. Four additional cwc QTLs were detected using the two-QTL model. Significant differences in chemical contents were observed among the populations from $\mathrm{NC}$ vs. OK, suggesting that QTLs interact with environmental location.

We have determined lignin content (averaging $24.8 \%$ on a dry weight basis) and syringyl to guaiacyl ratios (averaging 1.9:1.0) across all 310 full-sib Populus progeny. Glucan content, including fractions from cellulose and some subcomponents of hemicellulose, averaged $45.4 \%$. Estimates of mannan, arabinan and xylan averaged $2.7 \%, 0.5 \%$ and $17.0 \%$, respectively. Mean specific gravity was 0.34 and ranged from 0.24 to 0.48 . Glucan content and xylan content are negatively correlated $(\mathrm{r}=-0.91)$, as were arabinan content and extractive content $(\mathrm{r}=-0.76)$ and arabinan content and $\mathrm{S} / \mathrm{G}$ ratio $(\mathrm{r}=-0.73)$. There were no detectable correlations between lignin content and arabinans, lignin content and extractives content, extractives content and mannans, and glucans and extractives content. The genetic analysis indicated that there are multiple alleles contributed by each grandparental genotype. 


\section{INTRODUCTION}

Wood properties are known to vary between species and among genotypes within species. This variability is heritable and thus represents an opportunity to select for superior wood properties and improved product quality. Such selection is currently hampered by costly traditional biochemical assays (ca. $\$ 800$ per sample) and the necessity to wait until the trees are nearly mature to evaluate wood properties (i.e., ontogenic differences in wood properties). The combination of new analytical approaches to assay wood properties and the application of markeraided selection will increase the accuracy and reduce the time and costs associated with describing such properties.

Technical improvements have been made in procedures now available for assessing component wood properties. Overall wood density, fiber dimensions, and fiber characteristics can be accurately and quickly assessed using scanning x-ray densitometry and image analysis, as is being done on a large scale by forest product companies in Australia. Likewise, wood composition, i.e., cellulose, hemicellulose and lignin content, can be characterized by pyrolysis molecular beam mass spectrometry (pyMBMS) in a fraction of the time required by traditional wet chemical methods. These new techniques will increase the accuracy, lessen the time, and reduce the costs required to survey breeding populations for wood properties, thus facilitating the opportunity to select and improve future planting stocks.

Recent developments in molecular genetics will also help overcome the physical, economic, and biological constraints in assessing and improving wood properties. Genetic maps consisting of numerous molecular markers are now available in several economically important forest tree species. Each marker is associated with a specific chromosomal region. These markers may be linked to quantitative trait loci (QTL) that control component wood properties. As QTLs are identified they may then be used in marker-aided selection and breeding efforts to identify superior genotypes at any age. These markers could also expedite the isolation and characterization of specific genes and promoters that directly control wood properties. The isolation of wood property genes may then allow transformational modifications in wood properties.

The objectives of this project are: 1) to apply new and rapid analytical techniques for assessing component wood properties to segregating $F_{2}$ progeny populations of loblolly pine and hybrid poplar, 2) to map quantitative trait loci and identify molecular markers associated with wood properties in each of the above species and 3 ) to validate marker-aided selection methods for wood properties in loblolly pine and hybrid poplar.

\section{APPROACH}

Two three-generation segregating pedigrees of loblolly pine and two three-generation $\mathrm{F}_{2}$ pedigrees of hybrid poplar both with moderately saturated molecular maps were used in this study. More than 400 RFLP markers have been coalesced into a composite map for loblolly pine. Five of these markers have been previously linked to specific gravity measures in the $F_{2}$ progeny. Likewise, more than 500 RFLP, STS and RAPD markers have been used in the hybrid poplar map to identify QTLs associated with disease resistance, early growth rate, spring bud flush, and drought tolerance. These molecular maps were used to identify QTLs for component wood properties in each of the above species. Wood samples were obtained from ca. 170 loblolly pine genotypes and ca. 310 hybrid poplar genotypes. These samples were processed and used in assessment of earlywood and latewood density and cellulose/hemicellulose/lignin composition. Preliminarily, the parental and $F_{1}$ generations in each pedigree were screened for 
segregation in each wood property. A single pedigree in each species was selected for further analysis. At the same time, the analytical techniques, i.e., x-ray densitometry and pyMBMS, were optimized for the two species. The selected $\mathrm{F}_{2}$ progeny were characterized based on the above two techniques and information on each wood property was linked to the respective molecular maps. 


\title{
2. TWO HIGH-THROUGHPUT TECHNIQUES FOR DETERMINING WOOD PROPERTIES AS PART OF A MOLECULAR GENETICS ANALYSIS OF HYBRID POPLAR AND LOBLOLLY PINE
}

\begin{abstract}
Two new high-throughput techniques, computer tomography x-ray densitometry (CT scan) and pyrolysis molecular beam mass spectrometry (pyMBMS), coupled with quantitative trait loci (QTL) analysis, were tested as a means to overcome the time and cost associated with conventional characterization of biomass feedstock components. Applications of these two techniques were evaluated using hybrid poplar for the CT scan and loblolly pine for the pyMBMS. Segregating progeny from hybrid poplar varied in specific gravity, with individual mean estimates ranging between 0.21 and 0.54 . Progeny from loblolly pine varied in lignin, cellulose, and mannan contents, with individual mean estimates of lignin content ranging between 28.7 and $33.1 \%$, cellulose content between 28.8 and $43.5 \%$ and mannan content between 4.2 and $10.1 \%$. QTL analysis of the loblolly pine data suggested that eleven QTLs were associated with individual feedstock characteristics and that two QTLs for several feedstock components were linked to the same position on the loblolly pine genetic map. Each QTL individually accounted for 7 to $13 \%$ of the total phenotypic variation in associated loblolly pine feedstock components. (Ref. Tuskan et al. 1999. Appl. Biochem. Biotech. 77-79:55-65 and Davis et al. 2000. TAPPI Pulping Conf. Proc., p. 1077-1081).
\end{abstract}




\section{A RAPID METHOD FOR MEASURING SYRINGYL TO GUAIACYL RATIOS IN HARDWOODS USING PYROLYSIS MOLECULAR BEAM MASS SPECTROMETRY}

\footnotetext{
Abstract. A rapid method for estimating syringyl to guaiacyl (S/G) ratios in hardwoods is demonstrated using a molecular beam mass spectrometer to analyze the pyrolysis products of hybrid poplars. Projection to Latent Structure (PLS) models were constructed that can be used to estimate the S/G ratio of the hardwood samples. The PLS models were constructed using 13 different Populus deltoides $\mathrm{x}$ Populus nigra (DN) trees that had an S/G range of 1.98-2.62 and 16 different Populus trichocarpa $\times$ Populus deltoides (TD) trees that had an S/G range of 1.1-2.18 as measured by thioacidolysis. The PLS model developed had a root mean squared error of prediction of 0.17 . The method allows for rapid analysis on small amounts (10 to $30 \mathrm{mg}$ ) of biomass samples, generally requiring about 2 minutes per sample. (Ref. M. Davis et al. 2001. Holzforschung In review).
} 


\title{
4. IDENTIFICATION OF QTLS INFLUENCING WOOD PROPERTY TRAITS IN LOBLOLLY PINE (PINUS TAEDA L.). I. PHYSICAL WOOD PROPERTIES
}

\begin{abstract}
Physical wood property traits for loblolly pine (Pinus taeda L.) were analyzed for the presence of quantitative trait loci (QTLs) in a three-generation outbred pedigree. These traits include wood specific gravity (wsg), volume percentage of latewood (vol\%), and microfibril angle (mfa). Phenotypic data were collected for rings 2-11 for wsg and vol\%, and rings 3, 5 and 7 for mfa. Both early- and latewood were analyzed for each trait. An interval mapping approach designed for an outbred pedigree was used to estimate the number of QTLs, the magnitude of QTL effects, and their genomic position. Nine unique QTLs were detected for composite traits (average of all rings) for wsg, five for vol\%, and five for mfa. The majority of these QTLs were verified by analyses of individual-ring traits. Additional QTLs for each trait were also detected by these individual-ring analyses. Most QTLs for wsg were specific to either earlywood or latewood, whereas each QTL for mfa was detected for both early- and latewood. Before these QTLs are utilized in a breeding program, they should be verified in larger experiments and in different genetic and environmental backgrounds. (Ref. Sewell et al. 2000. Theoretical and Applied Genetics 101:1273-1281.)
\end{abstract}




\title{
5. IDENTIFICATION OF QTLS INFLUENCING WOOD PROPERTY TRAITS IN LOBLOLLY PINE (PINUS TAEDA L.). II. CHEMICAL WOOD PROPERTIES
}

\begin{abstract}
Chemical wood property traits for loblolly pine (Pinus taeda L.) were analyzed for the presence of quantitative trait loci (QTLs) in a three-generation outbred pedigree. These traits were assayed using pyrolysis molecular beam mass spectrometry and include spectral peak values associated with various carbohydrates, a five-carbon hemicellulose sugar, a six-carbon alpha-cellulose sugar, and lignin. Models for projection to latent structures (PLS) were used to predict the chemical composition of cell walls (i.e., alpha-cellulose, galactans, and lignin) from mass spectral data using multivariate statistics. Data for both early- and latewood from the fifth ring were analyzed for each trait. An interval mapping approach designed for an outbred pedigree was used to estimate the number of QTLs, the magnitude of QTL effects, and their genomic position. Twelve unique QTLs influencing cell wall chemistry (cwc) were detected using the oneQTL model, and most QTLs (75\%) were verified by analyses of multiple peak or PLS values.

Four additional cwc QTLs were detected using the two-QTL model. Significant differences in chemical contents were observed among the populations from North Carolina vs. Oklahoma, and results from genotype $\mathrm{x}$ environment analyses suggest that QTLs interact with environmental location. QTLs should be verified in larger experiments and in different genetic and environmental backgrounds. QTL mapping will help towards eventually identifying genes having major effect on chemical wood properties. (Ref. Sewell et al. 2001. Theoretical and Applied Genetics In press)
\end{abstract}




\section{GENETIC VARIATION IN PHYSICAL AND CHEMICAL WOOD PROPERTY TRAITS IN HYBRID POPLAR (POPULUS SPP.)}

Extended Abstract. Pyrolysis-molecular beam mass spectrometry (pyMBMS) and computer tomography x-ray densitometry (CT scan) techniques have been used to determine the chemical composition and specific gravity, respectively, in two segregating pedigrees (family 331 and family 355) of hybrid poplar (Populus spp.). Phenotypic data from these two techniques have been used to determine phenotypic and genetic correlations among cell wall chemical composition traits and wood specific gravity values, as well as provide estimates of number and magnitude of quantitative trait loci (QTL) for each trait. Two separate, 4-year-old $\mathrm{F}_{2}$ pedigrees have been analyzed, each containing approximately 175 clonally replicated and fertigated progeny. Diameter at breast height at the end of the fourth growing season ranged from 2.8 to $15.8 \mathrm{~cm}$ in family 331 and 1.0 to $12.5 \mathrm{~cm}$ in family 355 . Lignin values from the penultimate ring averaged $24.8 \%$ on a dry weight basis and syringyl to guaiacyl ratios (S/G ratio) averaged 1.9 across all progeny. Glucan content, including fractions from cellulose and some subcomponents of hemicellulose, averaged $45.4 \%$. Estimates of mannan, arabinan and xylan averaged $2.7 \%, 0.5 \%$ and $17.0 \%$, respectively. Mean specific gravity was 0.34 and ranged from 0.24 to 0.48 . There was a negative correlation between glucan content and xylan content $(\mathrm{r}=-0.91)$, with the next highest correlations occurring between arabinan content and extractive content $(\mathrm{r}=-0.76)$ and arabinan content and $\mathrm{S} / \mathrm{G}$ ratio $(\mathrm{r}=-0.73)$. There were no detectable correlations between lignin content and arabinans, lignin content and extractives content, extractives content and mannans, and glucans and extractives content. The genetic analysis indicated that there are multiple alleles contributed by each grandparental genotype.

QTL analysis for the base population in hybrid poplar has been completed using cell wall composition data collected on hybrid poplar samples. As of today, no QTLs have been detected for physical or chemical cell wall properties. We originally felt that $P$. trichocarpa and $P$. deltoides would be strongly differentiated given their taxonomic relationship and their dissimilar geographic distribution, thus allowing for a conventional inbred $\mathrm{F}_{2}$ segregational QTL analysis. This approach has worked for many other phenotypes (150 total), including overall growth, stem, limb and leaf traits, disease resistance traits, rooting habit, and many physiological traits.

Apparently, for cell wall phenotypes, a more informative (i.e., 4 alleles per locus) genetic model is required to detect QTLs. We are in the process of identifying polymorphic microsatellite markers for Populus that will allow us to associate unique markers to each grandparental allele. We have sequenced about $1.3 \mathrm{Mb}$ of genomic DNA and have found several hundred potential simple, compound and complex SSRs. Linkage maps have been created with 156 of these markers, representing 17 linkage groups. Approximately 50 of these SSRs are fully informative and are evenly dispersed across the genome. (Ref. Tuskan, G.A., D.C. West, M. Davis and H.D. Bradshaw. 1999. Proc. $2^{\text {nd }}$ International Poplar Symposium, INRA, Orleans, France, September 13-17, 1999. Pp. 93.) 


\title{
7. GENETIC MODIFICATION OF SHORT ROTATION POPLAR WOOD PROPERTIES FOR ETHANOL FUEL AND FIBER PRODUCTION
}

\begin{abstract}
Opportunities for matching wood chemical and physical properties to manufacturing and product requirements via genetic modification have long been recognized. Exploitation is now feasible due to advances in trait measurement, breeding, genetic mapping and marker-aided selection, and genetic transformation technologies. With regard to classical selection and breeding of short-rotation poplars, genetic parameters are favorable for decreasing lignin content and increasing specific gravity, but less so for increasing cellulose content. Knowledge of functional genomics is expanding, as is that needed for eventual application of marker-aided breeding, trait dissection, candidate gene identification, and gene isolation. Research on gene transfer has yielded transgenic poplars with decreased lignin and increased cellulose contents, but otherwise normal growth and development. Until effective marker-aided breeding technologies become available, the most promising approach for enhancing ethanol fuel and fiber production and processing efficiencies centers on selecting and breeding poplars for high wood substance yields and genetically transforming them for modified lignin and cellulose contents. (Ref. Dinus et al. 2001. Critical Reviews in Plant Sciences 20:51-69.)
\end{abstract}




\section{OVERALL SUMMARY AND CONCLUSIONS}

We successfully completed the first objective of this study in the development of the pyMBMS technique for determining wood composition and the application of CT scan for determining wood density. These techniques have been applied to segregating families in both loblolly pine and hybrid poplar. Objective 2 has been partially completed. QTLs have successfully been identified for physical and chemical wood property traits in loblolly pine. However, attempts were made to do the same in hybrid poplar but the available linkage map only allowed a 2-allele dissection of the QTLs, i.e., one from the trichocarpa grandmother and one from the deltoides grandfather. As a result, resources were diverted to discover additional markers that would be fully informative (i.e., $\mathrm{H}_{1} \mathrm{H}_{2}$, where $\mathrm{H}=$ heterozygote). Several hundred SSRs markers have been developed and mapped in hybrid poplar Family 331. The analysis of the validation pedigree in loblolly pine (i.e., Objective 3 ) has been completed, and the results are currently being written for publication. However, the delay in time and the additional demands on the budget prevent us from completing objective 3 in poplar. The continuation of SSR discovery in hybrid poplar continues through follow-on funding made available via a subcomponent of a small grant (\$50K) from the U.S. Forest Service, respectively.

Phenotypic data indicate that wood chemistry and wood density vary greatly within individual families of loblolly pine and hybrid poplar. As indicated by QTL analyses in loblolly pine and traditional clonal testing in hybrid poplar these traits are under genetic control. It should be possible to capture this variation through traditional breeding methods in either species, particularly if vegetative propagation methods are available for commercial deployment. In addition, in loblolly pine, the detected QTLs generally accounted for a measurable portion of the total phenotypic variation, suggesting that marker-aided selection may be feasible. Data on QTL occurrence and significance in alternate families is being collected and evaluated. Finally, a publicly available library of SSR markers for Populus and Salix is being compiled. Once a sufficient number of fully informative SSR markers have been mapped, a QTL analysis will be conducted to determine if there are region in the Populus genome that account for variation in wood chemistry and wood density. It is anticipated that such QTLs exist. 


\section{FUNDING INFORMATION}

This project was funded by the DOE Office of Industrial Technologies under the Forest Products Industry of the Future Program, often commonly referred to as the Forest Products Agenda 2020. The area of this activity was Forest Sustainability. Cost share was provided by the participating companies as shown in Table 1. Some of the funds received by ORNL was sent to subcontractors as shown in Table 2.

Table 1. Budget by Year and Source

\begin{tabular}{|c|c|c|c|c|c|c|}
\hline APPROVED BUDGET (\$K) & \multicolumn{3}{|c|}{ Annual } & \multicolumn{3}{|c|}{ Cumulative } \\
\hline Phase (Period) & $\mathrm{DOE}$ & $\begin{array}{c}\text { Cost } \\
\text { Share }\end{array}$ & Total & $\mathrm{DOE}$ & $\begin{array}{l}\text { Cost } \\
\text { Share }\end{array}$ & Total \\
\hline Year $1(06 / 1 / 96$ to $05 / 31 / 97)$ & 210.0 & 370.0 & 580.0 & 210.0 & 370.0 & 580.0 \\
\hline Year $2(06 / 1 / 97$ to $02 / 1 / 98)$ & 260.0 & 110.0 & 370.0 & 470.0 & 480.0 & 950.0 \\
\hline Year $3(02 / 1 / 98 \text { to } 09 / 30 / 99)^{*}$ & 230.0 & 110.0 & 340.0 & 700.0 & 590.0 & 1290.0 \\
\hline Totals & 700.0 & 590.0 & 1290.0 & & & \\
\hline
\end{tabular}

Table 2. Subcontractor Funds

\begin{tabular}{|lccc|}
\hline \multicolumn{1}{|c|}{ SUBCONTRACTS (\$K) } & \multicolumn{3}{c|}{ Annual } \\
\hline \multicolumn{1}{|c|}{ Phase (Period) } & $\begin{array}{c}\text { Ron } \\
\text { Dinus }\end{array}$ & $\begin{array}{c}\text { Un. of } \\
\text { Washington }\end{array}$ & NREL \\
\hline Year 1 (06/1/96 to 05/31/97) & 30 & 40 & 0 \\
Year 2 (06/1/97 to 02/1/98) & 30 & 20 & 0 \\
Year 3 (02/1/98 to 09/30/99)* & 18 & 10 & 50 \\
\cline { 2 - 4 } Totals & 78 & 70 & 50 \\
\hline \multirow{4}{*}{ *Year 3 was longer than 12 months to allow 3 full years of effort on the project, } \\
compensating for the shorter period of effort with year 2 funding. \\
\hline
\end{tabular}




\section{PRESENTATIONS, SCIENTIFIC PUBLICATIONS, AND WEB SITES}

\section{PRESENTATIONS}

Mapping quantitative traits for wood quality and wood chemistry in loblolly pine. Plant and Animal Genome VI. January 1998. San Diego, CA.

Mapping quantitative traits for wood properties in loblolly pine. Conifer Biotechnology Working Group. June 7-11, 1998. Rutgers University, Rutgers, NJ.

Rapid analysis of wood composition using a combination of pyrolysis mass spectroscopy and multivariate analysis. SRIEG meeting. July 1998. Atlanta, GA.

Application of high-throughput computer-assisted x-ray tomography to segregating populations of hybrid poplar. SRIEG meeting. July 1998. Atlanta, GA.

Mapping quantitative traits for wood properties in loblolly pine. SRIEG meeting. July 1998. Atlanta, GA.

Development and validation of marker-aided selection methods for wood property traits in loblolly pine and hybrid poplar. North American Forest Biology Workshop. June 1998. Victoria, BC.

Mapping quantitative traits for physical and chemical wood properties in loblolly pine (Pinus taeda L.). IUFRO Conf. Future of Pine Genomics. July 11-13, 1999. New Orleans, LA.

Application of pyrolysis molecular beam mass spectrometry and computer tomography for determining the chemical and physical cell wall structure of loblolly pine and hybrid poplar. Forest Products Society Meeting. June 1999. Boise, ID.

Variation in cell wall properties in Populus. $2^{\text {nd }}$ International Poplar Symposium. September 1999. Orleans, France.

Application of pyrolysis molecular beam mass spectrometry for the determination of loblolly pine and hybrid poplar cell wall composition. TAPPI Conference. October 1999. Orlando, FL.

Mapping quantitative traits for physical and chemical wood properties in loblolly pine (Pinus taeda L.). TAPPI Conference. October 1999. Orlando, FL.

\section{SCIENTIFIC PUBLICATIONS}

Tuskan, G.A., D. West, H.D. Bradshaw, D. Neale, M. Sewell, N. Wheeler, R. Megraw, K. Jech, A. Wiselogel, R. Evans, C. Elam, M. Davis and R. Dinus. 1999. Two high-throughput techniques for determining wood properties as part of a molecular genetics analysis of loblolly pine and hybrid poplar. Applied Biochem. Biotech. 77-79:1-11.

Davis, M., C. Elam, R. Megraw, A. Wiselogel, M. Sewell, N. Wheeler, R. Evans, K. Jech, D. Neale, G. Tuskan, D. West and R. Dinus. 2000. Application of pyrolysis molecular beam mass spectrometry for the determination of loblolly pine and hybrid poplar cell wall composition. TAPPI Pulping Conf. Proc., p. 1077-1081. 
Sewell, M.M., D. L. Bassoni, R. A. Megraw, N. C. Wheeler and D. B. Neale. 2000.

Identification of QTLs influencing wood property traits in loblolly pine (Pinus taeda L.). I.

Physical wood properties. Theoretical and Applied Genetics 101:1273-1281.

Sewell, M.M., M. F. Davis, G. A. Tuskan, N. C. Wheeler, C. Elam, D. L. Bassoni and D. B. Neale. 2001. Identification of QTLs influencing wood property traits in loblolly pine (Pinus taeda L.). II. Chemical wood properties. Theoretical and Applied Genetics In press.

Dinus, R.J., P. Payne, M.M. Sewell, V.L. Chiang and G.A. Tuskan. 2001. Genetic modification of short rotation poplar wood properties for ethanol fuel and fiber production. Critical Reviews in Plant Sciences 20:51-69.

Davis, M., R. Dinus and G. Tuskan. 2001. A rapid method for measuring syringyl to guaiacyl ratios in hardwoods using pyrolysis molecular beam mass spectrometry. Holzforschung In review.

\section{WEB SITES}

For the Populus genetic map and molecular markers are available at: http://poplar2.cfr.washington.edu/pmgc/ssr/pmgcssr.htm

For the loblolly pine genetic map and molecular markers are available at: hitp:/tdendrome.ucdavis.edu/ mseweth/indexz.htmm 
ORNL/TM-2001/41

\section{INTERNAL DISTRIBUTION}

1. P. Anderson

2. J. Cushman

3. M. Downing

4. A. Ehrenshaft

5. R. Graham

6. L. Gunter

7. S. G. Hildebrand

8. L. Kszos

9. S. McLaughlin

10. E. Peele
11. R. Perlack

12. J. Scurlock

13. S. Sokhansanj

14. V. Tolbert

15. T. Tschaplinski

16. G. Tuskan

17. M. Walsh

18. L. Wright

19-21. ESD Library

22. ORNL Laboratory Records-RC

\section{EXTERNAL DISTRIBUTION}

23. H. Toby Bradshaw, University of Washington, Center for Urban Horticulture, GF-15, Seattle, WA 98195

24. Mark Davis, National Renewable Energy Laboratory, 1617 Cole Blvd., Golden, CO 80401

25. Ron Dinus, 2490 Goshen Road, Bellingham, WA 98226-9556

26. Carolyn Elam, National Renewable Energy Laboratory, 1617 Cole Blvd., Golden, CO 80401

27. Robert Evans, National Renewable Energy Laboratory, 1617 Cole Blvd., Golden, CO 80401

28. Keith Jech, Weyerhaeuser Corporation, Forest Resources Research Center, 505 N. Pearl, P.O. Box 420, Centralia, WA 98531

29. Bob Megraw, Weyerhaeuser Corporation, Forest Resources Research Center, 505 N. Pearl, P.O. Box 420, Centralia, WA 98531

30. David Neale, USDA - Forest Service, P.O. Box 245, Berkeley, CA 94701

31. Mitchell Sewell, USDA - Forest Service, P.O. Box 245, Berkeley, CA 94701

32. Chuck Weirman, Boise Cascade Corporation, Fiber Farm, P.O. Box 500, Wallula, WA 99363

33. Nich Wheeler, Weyerhaeuser Corporation, Forest Resources Research Center, 505 N. Pearl, P.O. Box 420, Centralia, WA 98531 